\title{
Estruturas de poder - patronato, honra e prestígio nas representações discursivas das moedas de Aelia Capitolina e Cesareia no século III EC
}

\author{
Gladys Mary Santos Sales*
}

SALES, G. M. S. Estruturas de poder - patronato, honra e prestígio nas representações discursivas das moedas de Aelia Capitolina e Cesareia no século III EC. R. Museu Arq. Etn., 32: 179-190, 2019.

Resumo: A presente pesquisa tem por objetivo a compreensão das estruturas de poder - patronato, honra e prestígio - observadas a partir das moedas cunhadas em duas províncias da Palestina Romana (Aelia Capitolina e Cesareia) no século III EC. Pretende-se por meio desta análise numismática obter dados referentes à emissão, circulação, iconografia e legendas monetárias, para o entendimento dos possíveis padrões de interações político-administrativa, sociocultural e religiosa de Roma com as elites locais e vice-versa relacionados ao patrocínio provincial. $\mathrm{O}$ discurso de poder representado nas moedas refere-se ao elemento linguístico que é construção social, por isso, as análises desta pesquisa apoiam-se nas epistemologias arqueológicas, numismáticas, antropológicas, sociológicas, históricas existentes, e na contribuição da teoria linguística da Multimodalidade, para a verificação da intencionalidade persuasiva presente nas moedas, associada ao contexto sociocultural do século III EC na Palestina Romana. Faz-se necessária a reflexão da cultura material (moeda) e suas representações imateriais (estruturas de poder), para o entendimento de dois questionamentos principais: i) quais princípios socioculturais alicerçaram o patrocínio das elites locais em relação à comunidade provincial na Antiguidade Tardia? ii) qual a contribuição da amoedação da Palestina Romana para veiculação e legitimação das estruturas de poder na região, no século III EC?

Palavras-chave: Monetarização; Iconografia monetária; Palestina romana; Poder e patronato.

\section{Introdução}

Z sta comunicação refere-se à dissertação

Ce mestrado relacionada às estruturas de poder - patronato, honra e prestígio - observadas

$\left.{ }^{*}\right)$ Doutoranda em Arqueologia pelo MAE-USP. Pesquisadora do LARP-MAE/USP a partir das moedas cunhadas em duas províncias da Palestina Romana (Aelia Capitolina e Cesareia) no século III EC, com vistas à constatação da posição ideológica presente na amoedação, ${ }^{1}$ associada ao contexto sociocultural desse século.

(1) O termo amoedação está relacionado à materialidade da cunhagem de moedas, e suas instâncias imateriais representadas no anverso e reverso do disco metálico conhecido por moeda. 
Estruturas de poder - patronato, honra e prestígio nas representações discursivas das moedas de Aelia Capitolina e Cesareia no século III EC

R. Museu Arq. Etn., 32: 179-190, 2019.

Sabe-se que os estudos arqueológicos desenvolvidos nos séculos XIX e início do XX sobre o Mediterrâneo Antigo, especificamente as pesquisas referentes à Palestina Romana, foram amplamente marcados pelo unilateralismo da experiência do domínio do Império Romano nesta região. Tratava-se de pesquisas cuja visão polarizada da relação existente entre Roma e a comunidade provincial de Aelia Capitolina e Cesareia, promovia o uso constante de oposições binárias - 'centro/periferia'; 'civilizado/ bárbaro' - na compreensão das realidades antigas.

De fato, diversos estudos, nos últimos anos, têm ressaltado o impacto duradouro dessa herança colonialista sobre os modelos e os conceitos utilizados desde então pelos estudiosos da Antiguidade (Bernal 1987; Hingley 2000). No entanto, nenhuma tradição foi tão profundamente marcada pelo moderno colonialismo e pelo processo de descolonização que se seguiu do que os estudos sobre o Império Romano.

Essa identificação contrastante entre passado e presente resultou, por parte dos ideólogos, divulgadores e estudiosos do período colonial, na criação do termo 'romanização', conceito em desuso, uma vez que, se sabe que no processo de conquista, houve por parte da comunidade local, uma série de revoltas contra o Império Romano, que têm evidenciado a resistência das províncias à ocupação estrangeira (Mattingly 1996; Munzi 2001).

No final da década de 1990 e início dos anos 2000, a Arqueologia acadêmica do mundo romano no Brasil experimentou grande vigor (Guarinello 1994, 1995, 2005, 2006; Fleming 2001, 2014; Funari 1997, 2003a, 2003b, 2005, 2006, 2008a, 2008b), e além da participação de alguns brasileiros em escavações de sítios romanos no Ocidente (Garraffoni, Cavicchioli \& Silva 2001); uma equipe brasileira escavou pela primeira vez um sítio romano no Oriente (Marshall 2003).

As fronteiras de pesquisa foram dessa forma estendidas para Israel e o trabalho realizado na área E do sítio romano de Apollonia desenterrou um edifício que foi identificado como uma villa maritima (Rech 2003; Roll \& Tal 1999), datada entre o primeiro e início do segundo século EC.
Ressalta-se nas atuais discussões brasileiras sobre o Império Romano, a importância das atividades desenvolvidas na Universidade de São Paulo - USP, no Laboratório de Arqueologia Romana Provincial, coordenado pela Profa. Dra. Maria Isabel D'Agostino Fleming e Prof. Dr. Vagner Carvalheiro Porto - que tem pesquisadores que se dedicam a estudar essa região, como os recentes estudos de Marcio Teixeira Bastos (Cristianização dos Espaços na Antiguidade Tardia: $\mathrm{O}$ caso de Apollonia-Arsuf, dissertação de mestrado, 2011; Análise e distribuição espacial de lamparinas romanas de disco: o caso das províncias da Palestina e do norte da África, tese de doutorado, 2016).

Recentemente, o Laboratório de Arqueologia Romana Provincial - LARP/USP foi representado pelas pesquisadoras Profa. Gladys Mary Santos Sales, Claudia Gradim e Dra. Lygia Ferreira Rocco nas escavações em Israel, organizadas pela Universidade Hebraica de Jerusalém - Projeto Tiberíades em 2018, sob a coordenação da Profa. Dra. Katia Cytryn-Silverman.

Compreende-se que a Arqueologia se refere à construção do passado em consonância com o presente, em uma perspectiva crítica do futuro, por meio da convicção de que o registro arqueológico é algo socialmente construído, o que na definição de Funari (2003:15), a Arqueologia "[...] estuda, diretamente, a totalidade material apropriada pelas sociedades humanas, como parte de uma cultura total, material e imaterial, sem limitações de caráter cronológico".

Dando continuidade às programações acima mencionadas, esta pesquisa tem por objetivo a compreensão das estruturas de poder observadas nas moedas cunhadas em duas províncias da Palestina Romana (Aelia Capitolina e Cesareia) no século III EC, em uma perspectiva pós-colonialista.

\section{Contexto histórico e geográfico da pesquisa}

Esta pesquisa arqueológica tem por objetivo o entendimento das relações existentes entre Roma - especificamente do lado Oriental do Império - e as respectivas elites locais, na compreensão de sua integração com a comunidade provincial de Aelia Capitolina e Cesareia na Palestina 
romana, no século III EC, por meio do diálogo entre numismática e fonte textual, na compreensão da tríade - patrocínio, honra e prestígio no período de ocupação romana na região.

Segundo Norberto Guarinello, é importante ressaltar que havia duas áreas de dominação romana - Oriente e Ocidente, passíveis de estratégias de dominação diferentes. No Ocidente romano houve a difusão de todo um modo de 'ser romano' - baseado na difusão do latim, padrões arquitetônicos e nas práticas que difundiam os ideais latinos, tais como: as vestimentas, os fora e o anfiteatro. Em contrapartida, no Oriente, já havia uma vida urbana pré-romana, além do helenismo, que difundiu a língua grega. Sendo assim, as estratégias romanas no Oriente visavam reforçar características helenísticas que já haviam interagido com as culturas daquela região (Guarinello 2008:13).

Após a supressão da revolta de Bar Kokhba e as mudanças estruturais e fundamentais na Palestina Romana, o terceiro século da EC foi marcado por profundas mudanças no mundo romano.

Durante muito tempo, o período conhecido como Antiguidade Tardia ou Baixo Império, ficou associado à decadência do Mundo Romano Ocidental, ascensão do Cristianismo e as invasões dos povos germânicos, conhecidos pejorativamente como "bárbaros". Roma entre os séculos III e V EC, estava relacionada à ideia de declínio. Na realidade, a Antiguidade Tardia não é um período decadente, e sim de transformação. Todo o Império sofreu um processo único que irá sobreviver à "Queda de Roma", pelos Hérulos de Odoacro, em 476 EC (Bijovsky 2001:b13).

Após o último membro da dinastia Severa morrer em 235, um prolongado período de guerra civil eclodiu. Ao longo dos cinquenta anos seguintes houve uma rápida sucessão de pretendentes ao trono romano, apenas um dos quais morreu de morte natural (os outros foram assassinados ou mortos em batalha). A instabilidade no trono afetou todos os aspectos da vida romana, resultando em inflação e desvalorização da moeda, assim como invasões hostis de outros povos nas fronteiras do império. Pela primeira vez em séculos, uma nova muralha foi construída em torno da cidade de Roma.
Politicamente, esse período foi dividido pela historiografia em dois momentos distintos: um primeiro momento, chamado de Anarquia Militar (235-268 EC), em que os imperadores eram nomeados por seus soldados. A outra fase é a dos Imperadores Ilírios (268-284 EC), sendo caracterizada por um grupo de governantes originários da Ilíria (atual Europa Oriental, perto da Albânia).

Entre os anos 238 e 285 EC, dezenove imperadores ocuparam o poder em Roma. Nenhum deles conseguiu atuar de forma ativa com o Senado, colocando Roma em uma crise institucional. No meio desse caos, era necessária uma série de reformas urgentes para salvar o Império.

Após o assassinato de Numeriano (283-284 EC), Caio Aurélio Valério Diocleciano, ilírio da Dalmácia, foi proclamado imperador pelos seus soldados. Apesar de possuir um nome ilustre, Valério, ele não descendia da aristocrática família romana do mesmo nome. Portanto, não era um patrício. Seu pai era um liberto, ex-escravo, da Dalmácia (Andreau 1993:187). Para evitar um fim igual ao dos seus antecessores, assassinado por seus soldados, tratou de apoiar-se em elementos de sua confiança, e do mesmo mundo social. Exemplo disto são os membros da futura tetrarquia, Galério (305-311 EC), seu adjunto, guardara gado nos Cárpatos; Maximiano (285/286-305 EC), antigo colega de armas.

Segundo Carlan (2013:69), no ano de 286 $\mathrm{EC}$, iniciou-se uma série de reformas que, por algum tempo, restauraram a ordem.

O sistema de diarquia foi ampliado para tetrarquia, com participações recíprocas de Galério e Constâncio Cloro como Césares, ambos ligados por grau de parentesco, através do matrimônio com as filhas dos respectivos Augustos.

Esse sistema de governo criado por Diocleciano, consistia no poder nas mãos de quatro homens (dois Augustos e dois Césares), que foi chamado de Tetrarquia, e cada um dos quatro governantes era denominado Tetrarca.

Para Carlan (2013:65), nesse período as casas de cunhagem foram ampliadas, a fim de satisfazer as obrigações da tetrarquia e as necessidades do comércio: obras públicas, aumento do efetivo militar e civil. Para isso, novas peças começam a circular com letras, na parte inferior 
Estruturas de poder - patronato, honra e prestígio nas representações discursivas das moedas de Aelia Capitolina e Cesareia no século III EC

R. Museu Arq. Etn., 32: 179-190, 2019.

do reverso da moeda, conhecida por exergo. Quando visível, podemos identificar o nome (espécie de sigla) do local da cunhagem.

Como modelo, Diocleciano copiou as monarquias orientais, nas quais tudo o que cercava o rei era considerado sagrado.

Desde a segunda metade do século III EC, o cristianismo começou a exercer um papel importante tanto na política, quanto na sociedade romana. No governo de Décio (imperador de 249 a 251 EC), ocorreu uma grande perseguição aos cristãos. Nesse período, o império vivia uma grave crise militar, e o imperador necessitava reafirmar a tradicional lealdade aos deuses tradicionalmente romanos.

\section{Metodologia}

Este estudo caracteriza-se como uma análise qualitativa, ou seja, uma pesquisa de cunho interpretativo que examina do ponto de vista crítico os catálogos numismáticos de moedas cunhadas no século III EC nas províncias Jerusalém/Aelia Capitolina e Cesareia, para o mapeamento dos locais de suas produções e circulações monetárias. A partir daí pretende-se inferir as questões ligadas a Estruturas de Poder - o patronato: honra e prestígio nessas províncias.

A pesquisa tem o apoio de fontes textuais: judaica e cristã, obras de Flávio Josefo (1948, 1950 e 2007), relatos de Dion Cassio (1995) e Eusébio de Cesareia (1994), as epistemologias da Linguística Sistêmico-Funcional de Halliday e Matthiessen
(2004) e seus colaboradores bem como a Multimodalidade de Kress e Van Leeuwen (1996).

\subsection{Dados}

Foram coletadas, inicialmente quarenta e cinco moedas cunhadas em Aelia Capitolina e quarenta e uma moedas de Cesareia em março de 2017, mas, para se evitar a multiplicidade e repetição na análise, dessas, foi analisada apenas uma, para uma visão geral da construção ideológica das estruturas de poder presentes nas escolhas imagéticas e discursivas das cunhagens provinciais do século III EC, conforme mostra a Tabela 1.

Tabela 1

\begin{tabular}{llll}
\hline No & $\begin{array}{l}\text { Imperador } \\
\text { romano }\end{array}$ & Século & Denominação \\
1 & Trajano & III EC & Æ $27 \mathrm{~mm}$, bronze, \\
& Décio Aelia Capitolina \\
& & & (Meshorer, Aelia 152) \\
\hline
\end{tabular}

Tabela 1. Moedas de Aelia Capitolina/Jerusalém e Cesareia.

Os contextos dessas cunhagens são respectivamente os seguintes, de acordo com a teoria de Registro que envolve os itens: Campo (assunto), Relações (sociedade da época envolvida do mercado de circulação das moedas) e Modo (o tipo de texto: gênero: cunhagem; modalidade: verbiagem e imagem; e formalidade: linguagem culta: valores e nomes), como mostra a Tabela 2 .

A amostragem numismática pode ser observada na Tabela 3.

Tabela 2

\begin{tabular}{ll}
\hline Fig. 2 - Moeda de & Campo: Cunhagem local do século III EC \\
Aelia Capitolina/ & Relações: Imperador Trajano Décio e a elite da província Aelia Capitolina/Je- \\
& rusalém do século III EC em parceria com as oficinas de cunhagem e mercado \\
& interno de circulação (população que utilizava a moeda). \\
& Modo: texto (imagem e verbiagem: Estruturas de poder observadas no status \\
& administrativo da província, lingua das legendas, refundação/nomeação da \\
& cidade) cunhado no período Romano Tardio como convém a uma oficina de \\
& cunhagem que é responsável pela circulação dos valores em bronze nas provín- \\
& cias autorizadas pelo Império Romano a bater moedas.
\end{tabular}

Tabela 2. O contexto dos dados. 
Tabela 3
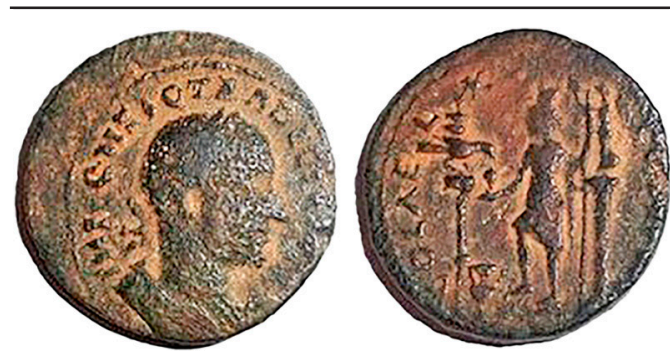

1) Autoridade Emissora: Magistrados sob Trajano Décio.

2) Característica de emissão/distinção de status: moeda local

3) Datação: 249-251 EC

4) Local da emissão: Aelia Capitolina, Palestina.

5) Anverso: busto radiado, drapeado e encouraçado de Trajano Décio, à direita.

Legendas de anverso: IMPC G MES Q TRA DECIVS AVG

Reverso: Tyche, à esquerda, segurando um busto humano e um longo cetro; na frente dela, águia legionária, à direita, a frente de um vexillum; atrás dela, Vitória sobre uma coluna; aos pés de Tyche um vaso.

Legendas de reverso: COL AEL KAP COM P F

6) Referências: Meshorer, Aelia 152

Tabela 3. Moedas de Aelia Capitolina/Jerusalém e Cesareia. Fonte: Adaptação da catalogação desenvolvida por Porto (2007).

\subsection{Procedimentos de análise}

A pesquisa tem o apoio das teorias, as quais atuam por meio das seguintes categorias de análise, conforme mostra a Tabela 4.

A análise divide-se em duas partes: (a) da legenda monetária (anverso e reverso) e (b) da iconografia (anverso e reverso).

Nesta seção, examino as escolhas lexicogramaticais das legendas monetárias do anverso e reverso das moedas provinciais do século III EC, para a verificação da existência de Estrutura de Poder: Patronato - honra e prestígio, nas cunhagens monetárias de Aelia Capitolina/
Jerusalém, sob o governo de Trajano Décio (século III EC) à luz das teorias numismáticas e da Linguística Sistêmico-Funcional (LSF) e seus colaboradores.

Apresento as imagens cunhadas no anverso e reverso da moeda de Aelia Capitolina/Jerusalém e suas interpretações.

\subsubsection{Análise e discussão geral}

As análises numismáticas - que tratam das cunhagens das moedas: Moeda de Aelia Capitolina/Jerusalém, do terceiro século da Era Comum, incluindo a questão das estruturas de poder representadas nas moedas provinciais, foco da presente pesquisa - tecem o processo persuasivo com base nas teorias arqueológicas e numismáticas (Lacroix 1974; Caltabiano 1998; Pérez 1986; Porto 2007) e da Linguística Sistêmico-Funcional (Halliday 1994 e seus colaboradores) em três fatores: a leitura crítica da moeda (multimodalidade, legitimização e a metafunção textual).

A legenda do anverso (Tabela 5) é circular e em latim, o que evidencia que o uso da língua oficial do império sobrepõe a língua e os dialetos locais nas cunhagens. O nome completo do imperador abreviado, Caesar Gaius Messius Quintus Traianus Decius Augustus, informa ao receptor a linhagem nobre do soberano. A legenda está sobreposta ao busto de Trajano Décio radiado, na divinização do imperador e seu reinado.

A legenda circular do reverso (Tabela 6) traz as siglas do nome da Colônia Aelia Capitolina Comodiana Pia Felix (Piedosa e Feliz), em latim na representação do status administrativo da província e de sua religiosidade.

Com relação ao estudo numismático com o aporte das teorias linguísticas evidenciou-se que a cunhagem provincial de Aelia Capitolina, apresenta estruturas de poder - status administrativo da província; legendas em latim, nomeação da cidade e a Legião Romana, e patronato honra e prestígio, da figura do imperador Caio Méssio Quinto Trajano Décio por meio dos processos persuasivos da metafunção textual Tema e Rema, Multimodalidade e Legitimização via emoção e voz de expert. 
Estruturas de poder - patronato, honra e prestígio nas representações discursivas das moedas de Aelia Capitolina e Cesareia no século III EC

R. Museu Arq. Etn., 32: 179-190, 2019.

Tabela 4

\begin{tabular}{|c|c|c|}
\hline Autores & & Procedimentos \\
\hline \multirow[t]{4}{*}{ Numismática } & Lacroix (1974) & $\begin{array}{l}\text { Localização } \\
\text { Produção e circulação } \\
\text { Origem mítico-religiosa }\end{array}$ \\
\hline & Caltabiano (1998) & $\begin{array}{l}\text { Símbolo (imagem e letra/legenda) } \\
\text { Iconografia da cunhagem (anverso e reverso) }\end{array}$ \\
\hline & Pérez (1986) & $\begin{array}{l}\text { Discurso ideológico } \\
\text { Relação imagem e legenda }\end{array}$ \\
\hline & Porto (2007) & $\begin{array}{l}\text { Status administrativo } \\
\text { Língua das legendas } \\
\text { Refundação/nomeação da cidade } \\
\text { Título de poder } \\
\text { Soberano } \\
\text { Linhagem } \\
\text { Título honorífico }\end{array}$ \\
\hline \multirow[t]{3}{*}{$\begin{array}{l}\text { LSF - } \\
\text { Análise da imagem } \\
\text { e verbiagem } \\
\text { (Multimodalidade) }\end{array}$} & Kress e Van Leeuwen (1996) & $\begin{array}{l}\text { Contato } \\
\text { Distância social } \\
\text { Dimensão horizontal } \\
\text { Dimensão vertical }\end{array}$ \\
\hline & Reyes (2011) & $\begin{array}{l}\text { Legitimização } \\
\text { Emoção } \\
\text { Voz de expert }\end{array}$ \\
\hline & Halliday e Matthiessen (2004) & $\begin{array}{l}\text { Metafunção textual } \\
\text { Tema e Rema }\end{array}$ \\
\hline
\end{tabular}

Tabela 4. Procedimentos de análise.

Tabela 5

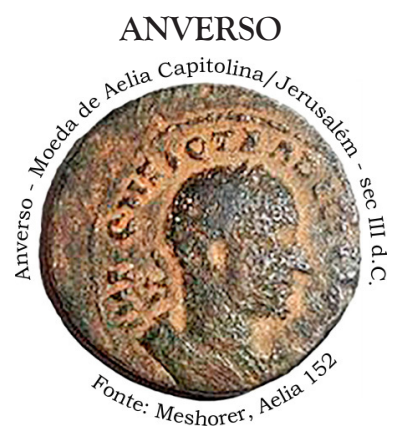

\begin{tabular}{llll} 
IMP & $\mathrm{C}$ & G MES Q TRA DECIVS & AVG \\
Título & Linhagem & Soberano & Título de poder \\
Honorífico & Título de poder & & \\
[Imperador=T] & [Caesar=T] & [Caio Méssio Quinto Trajano Décio=T] & [Augustus= T] \\
\hline
\end{tabular}

Tabela 5. Análise das legendas de anverso da moeda de Aelia Capitolina/ Jerusalém. 


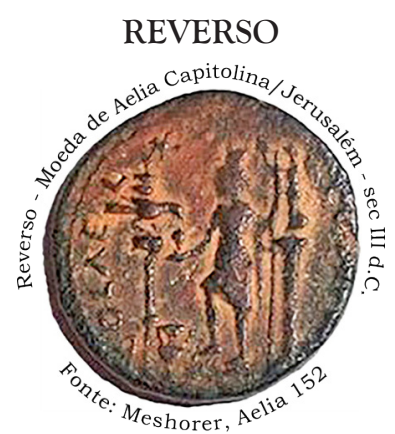

COL

\section{Status}

administrativo

[Colônia= R]

\section{[Aelia Capitolina Comodiana=R]}

\section{AEL KAP COM}

Localização

Refundação/ nomeação da cidade

Origem mítico-religiosa
PF

Título honorífico

[Piedosa e Feliz= R]

Tabela 6. Análise das legendas de reverso da moeda de Aelia Capitolina/ Jerusalém.

No anverso (Tabela 7) o tema central é o imperador, representado em trajes militares (encouraçado) e manto imperial (drapeado), na associação da figura do soberano à liderança do exército e vestimenta relacionada à nobreza.

No reverso (Tabela 8) o tema central é a imagem de Tyche que está orientada em direção ao Ocidente, à esquerda. As escolhas imagéticas que representam o poder imperial são a águia legionária e Vitória.

$\mathrm{Na}$ imagem do anverso (Tabela 7), a autoridade emissora utilizou vários recursos para a construção de sentido que contribuem para progressão temática, e assim faz o uso de elementos associados ao poder imperial, com imagens centralizadas no campo de impressão da moeda,

Tabela 7

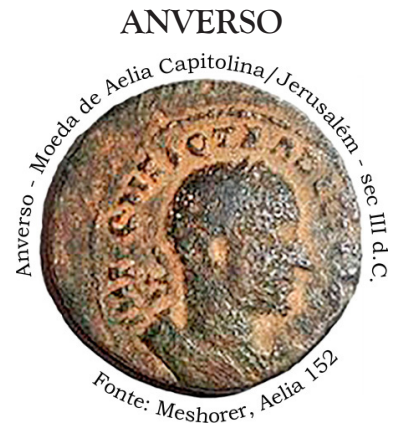

[Imperador Trajano Décio $=$ Tema e Voz de expert]

Enfoque: Tema + Voz de expert + Emoção

Interpretação: A imagem frontal do Imperador Trajano Décio surge estrategicamente como Tema e Voz de expert por ter sido cunhada em alto relevo no primeiro plano da moeda, com a finalidade de persuardir e mostrar à sociedade da época por meio do processo de [Legitimização via emoção, o poderio desta figura, que diretamente se articulava com as oficinas de cunhagem fosse por prestígio ou interesses escusos].

Tabela 7. Análise iconográfica da moeda de Aelia Capitolina/Jerusalém. 
Estruturas de poder - patronato, honra e prestígio nas representações discursivas das moedas de Aelia Capitolina e Cesareia no século III EC

R. Museu Arq. Etn., 32: 179-190, 2019.

\section{Tabela 8}

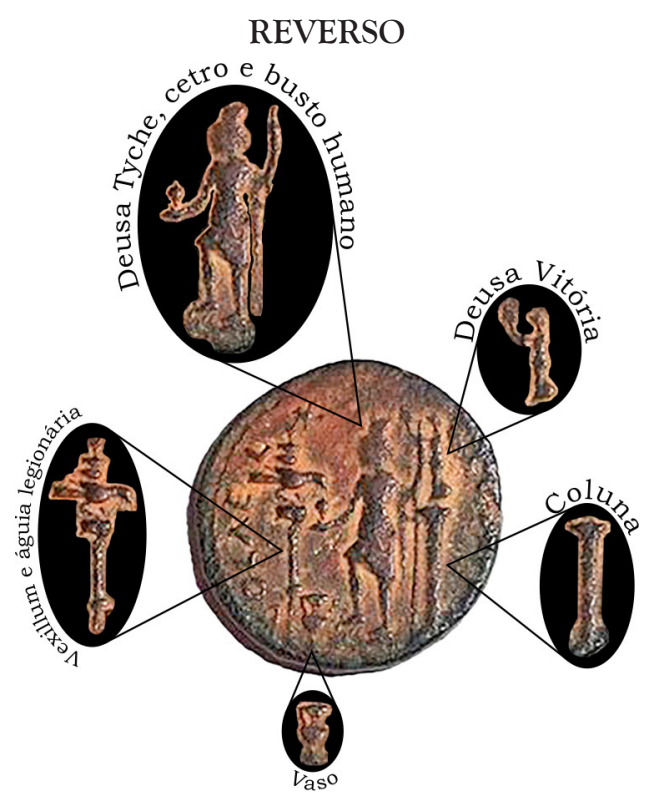

Podemos dividir a imagem do reverso em três partes:

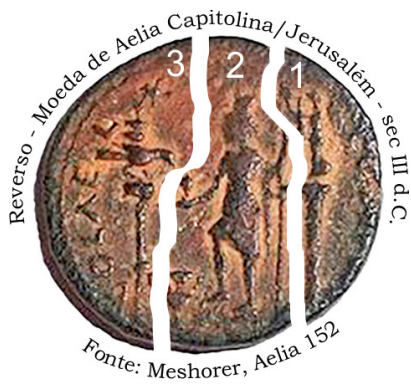

Primeira: [DeusaVitória = R; Voz de expert e Emoção] e [Coluna = R e Emoção]

Segunda: [Deusa Tyche = R; Voz de expert e Emoção]; [Cetro = R e Emoção]; [Busto humano= R; Voz de expert e Emoção] e [Vaso = R e Emoção]

Terceira: [Águia legionária = R e Emoção]; [Vexillum/estandarte = R e Emoção]

Tabela 8. Análise iconográfica da moeda de Aelia Capitolina/Jerusalém.

as quais chamam a atenção da comunidade provincial para a relevância da centralização do poder, bem como a cunhagem em alto relevo dos elementos em destaque e a maneira como foram dispostas na impressão além da disposição gráfica tais como o texto circular e superior, o tamanho de fonte selecionada, a borda ininterrupta dentre outros recursos.

Para Peréz (1986), todos esses recursos utilizados pela autoridade emissora são construtos textuais, que remetem à intenção comunicativa e/ou finalidade do texto, que está diretamente relacionada ao discurso ideológico emanado do Império às províncias.

Em relação à Localização da produção monetária, não há elementos iconográficos que identifiquem a proveniência da casa monetária, e dessa forma, a identificação da Produção e circulação desta moeda está vinculada à associação das informações da legenda com o contexto de achado.

Quanto à análise iconográfica de reverso - Tabela 8, a Origem mítico-religiosa está repre- 
sentada na imagem de Tyche e Vitória, deusas do panteão greco-romano.

\section{Os Símbolos (imagem e letra/legenda)} estão associados tanto no anverso, quanto no reverso, os quais promovem a construção e legitimação do poder imperial, com o uso do busto do imperador radiado, drapeado e encouraçado, em consonância com as divindades imperiais e a representação do poder militar de Roma na figura da águia legionária.

Os participantes cunhados no anverso e reverso desta moeda trazem sentido à mensagem na associação da Relação imagem e legenda, que viabilizam a veiculação das estruturas de poder por meio das escolhas imagéticas da Iconografia da cunhagem (anverso e reverso), na construção do Discurso ideológico da elite local em honra ao poder do Imperador Trajano Décio.

Conclui-se que a relação Tema-Rema serve para não só enfocar um elemento da imagem, mas também marcar parte da informação como a mensagem que, de fato, o autor quer que perdure na lembrança do leitor.

Transportando o que é válido na língua, para o meio visual, o que se poderia dizer em relação à cunhagem em foco é que: a verbiagem - IMP= Imperador, Caesar, Caio Méssio Quinto Trajano Décio e Augustus e a imagem do imperador, cunhadas no anverso da moeda são o Tema, enquanto os elementos da cultura mítico-religiosa - Deusa Vitória, águia legionária, cetro e Deusa Tyche, cunhadas no reverso, constituem o Rema, ou mesmo o Novo-Rema, porque são informações complementares ao Tema, consideradas cruciais na construção ideológica multimodal para persuadir a mente do leitor.

Porém toda a cunhagem é apresentada em um conjunto em que se misturam texto escrito, imagem, forma, relevo, peso do metal e cor bronze, meramente como informação neutra da cunhagem, mas que na subjancência traz uma carga ideológica, que tem como finalidade apresentar o poder do imperador da época, provocando assim as mais diversas emoções de respeito e apreço às autoridades desses séculos.

A verbiagem das cunhagens são legendas que, segundo Iasbeck (2000), são frases breves e compactas - sedutoras e significativas, nas quais os textos mais eficazes desprendem-se do caráter meramente referencial que os liga aos seus objetos, em vantagem das conotações simbólicas. É o que acontece com a verbiagem, em que as meras LETRAS INICIAIS dos imperadores adquirem um significado referencial: "grande" e com conotação simbólica, resultando no respeito da sociedade.

A multimodalidade - enunciado verbal e imagem das cunhagens apoiam-se na Metafunção Textual - Tema e Rema, nos processos de Legitimização - Voz de experts e emoção e nos fatores de contato, atitude e distância social.

\section{Considerações finais}

A pesquisa mostrou que a cunhagem provincial de Aelia Capitolina/Jerusalém e Cesareia do século III EC era totalmente de cunho ideológico, com a finalidade de persuadir a população local na crença de valores legitimadores do poder político, e a participar mesmo que de forma inconsciente das questões sociopolíticas, históricas e culturais da época, mas de forma hierarquizada, respeitando a rede multidirecional das estruturas de poder e patronato advindas das relações e negociações da Palestina romana com o Império.

Após a articulação das teorias arqueológica, linguísticas e numismáticas, conseguiu-se enxergar mecanismos epistemológicos e metodológicos que são suportes primordiais para a leitura crítica, que vão além das relações econômicas emanadas do estudo da cultura material. Assim, percebeu-se a possibilidade da interface do campo da Arqueologia com a Linguística Sistêmico-Funcional (LSF), então, pode-se afirmar com mais segurança que esta pesquisa referente às estruturas de poder e patronato observadas nas análises discursivas das moedas de Aelia Capitolina/Jerusalém e Cesareia no século III EC, pôde receber contribuições relevantes de estudos linguísticos.

A proposta metodológica deste estudo inovou ao articular duas ciências que apesar de terem conformações teórico-metodológicas de naturezas distintas, possuem aspectos semelhantes, principalmente por levarem em consideração o contexto sociopolítico, histórico, cultural 
Estruturas de poder - patronato, honra e prestígio nas representações discursivas das moedas de Aelia Capitolina e Cesareia no século III EC

R. Museu Arq. Etn., 32: 179-190, 2019.

e situacional imediato, nos quais se situam as problemáticas sociais e as relações interpessoais do mundo real, que transcendem a própria época histórica. Portanto, considera-se que as reflexões feitas com embasamento nas abordagens teóricas e metodológicas na convergência da Arqueologia com a LSF foram primordiais na compreensão dos aspectos iconográficos e textuais das moedas provinciais na antiguidade tardia.

Verificou-se também a consonância entre a articulação das teorias embasadas nesta pesquisa, uma vez que seus aspectos se assemelham pela preocupação não só de solucionar os problemas em situações contextualizadas, mas também fazer interface com as diversas áreas do conhecimento com a responsabilidade de sempre estarem revendo e refletindo ações, métodos teóricos e metodologias utilizadas, além de produzirem conhecimento de qualidade que poderão contribuir satisfatoriamente para outras áreas do conhecimento, as quais pretendam desenvolver uma análise pós-colonial no campo histórico-arqueológico.

As análises foram direcionadas por dois questionamentos principais - i) Quais princípios socioculturais alicerçaram o patrocínio das elites locais em relação à comunidade provincial na Antiguidade Tardia? ii) Qual a contribuição da amoedação da Palestina Romana para veiculação e legitimação das estruturas de poder na região, no século III EC?

As discussões fundamentadas nas teorias de Polanyi (1944) evidenciaram que o sistema de trocas nas sociedades antigas encontrava-se imbricado nas relações socioculturais e religiosas, conforme enunciado da primeira pergunta de pesquisa, que comprovou a relevância social na construção do sistema de trocas nas comunidades provinciais.

Com relação à segunda pergunta sobre a contribuição da amoedação da Palestina Romana para veiculação e legitimação das estruturas de poder e patronato na região, verificou-se pelas epistemologias numismáticas de Lacroix (1974), Caltabiano (1998), Porto (2007) e Pérez (1986), o entendimento de que as imagens monetárias da Palestina romana do séc. III EC, são representações discursivas de estruturas de poder: patronato - honra e prestígio, uma vez que, imagens, símbolos e palavras legitimavam o poder romano sobre as províncias.

Acredito que esta pesquisa possa contribuir de forma satisfatória para as epistemologias arqueológicas com relação à análise monetária, uma vez que apresentou suportes analíticos eficazes na leitura iconográfica e textual do anverso e reverso das moedas de Aelia Capitolina/ Jerusalém e Cesareia.

Penso que sempre haja a possibilidade de se repensar outros modos de teorizar e fazer análise de moedas, que possa surgir, de fato, a reflexão, na qual a investigação é fundamentalmente centrada no contexto aplicado, em que há mudanças relacionas à vida sociocultural, política e histórica, arraigada de interesses ideológicos.

Finalizo com a convicção de que todos os pesquisadores na área $\mathrm{d}$ a Arqueologia, que investigam a construção do significado nas cunhagens, precisam situar o seu trabalho nas contingências e vicissitudes sociopolíticas, históricas e culturais e não simplesmente indagar sobre a que interesses seu trabalho serve ou simplesmente desenvolver mera descrição do discurso impresso na cultura material. ${ }^{2}$
(2) Agradecimentos: ao onipotente Deus, pelas oportunidades e por dar-me forças para a realização do sonho de cursar o doutorado em Arqueologia no Museu de Arqueologia e Etnologia da Universidade de São Paulo - MAE/ USP. Ao Prof. Dr. Vagner Carvalheiro Porto, pela incansável orientação no processo de desenvolvimento de minhas pesquisas, constante dedicação e pelas excelentes aulas ministradas, que abordaram métodos teóricos significativos de muita relevância social. À minha amada mãe Merenice Santos Sales, meu tudo! Ao meu esposo Nelson, à pequena Ashley, aos meus amados irmãos: Eduardo, Elaine, Gleids e Helton. 
SALES, G. M. S. The power structures - patronage, honour and prestige - observed in the coins struck in two provinces of Roman Palestine (Aelia Capitolina and Caesarea) in the 3rd century CE. R. Museu Arq. Etn., 32: 179-190, 2019.

Abstract: The present work aims at understanding the power structures patronage, honour and prestige - observed in the coins struck in two provinces of Roman Palestine (Aelia Capitolina and Caesarea) in the 3rd century AD. Through this numismatic analysis we intend to obtain data related to the emission, circulation, iconography and monetary legends, in order to understand possible patterns of political, administrative, sociocultural and religious interactions between Rome and the local élites and vice-versa, related to provincial patronage. The discourse of power embedded in the coins is related to the linguistic element, which is a social construct. Therefore, the analyses contained in this research are supported by the existing archaeological, numismatic, anthropological, sociological, and historical theories, as well as contributions by the linguistic theory of Multimodality, seeking to verify the persuasive intentionality present in the coins, associated to the sociocultural context of Roman Palestine in the 3rd century CE. It is necessary to reflect upon the material culture (coin) and its immaterial representations (power structures), in order to investigate two main questions: i) Which sociocultural principles constituted the foundations of the local élite's patronage toward the provincial community in late Antiquity? ii) What was the contribution of Roman Palestine coinage to the channelling and legitimation of the power structures in the region in the 3rd century CE?

Keywords: Monetization; Monetary Iconography; Roman Palestine; Power and patronage.

\section{Referências bibliográficas}

Andreau, J. 1993. Il Liberto. In: Giardina, A. (Ed.) L'Uomo Romano. Prima edizione. Editori Laterza, Roma.

Bernal, M. 1987. Black Athena: Afroasiatic Roots of Classical Civilization, Volume I: The Fabrication of Ancient Greece, 1785-1985. Rutgers University Press, New Brunswick.

Bijovsky, G. I. 2000-2002.The Currency of the Fifth Century C.E. in Palestine - Some Reflections in Light of the Numismatic Evidence. Israel Numismatic Journal, vol. 14: 196 - 210.

Bijovsky, G. I.; G; Raphael, K. 2014. The Coin Hoard from Caesarea Maritima and the 363 CE Earthquake. Israel Numismatic Journal, vol. 9: 173-191.

Caltabiano, M. C. 1998. Immagini-parola, grammatica e sintassi di un lessico iconografico monetale. In: ARSLAN, A. E. (a cura di) La "parola" delle immagini e delle forme di scrittura: modi e tecniche di comunicazione nel mondo antico. Oudheid. Messina: 57-74.

Carlan, C. U. 2013. Moeda e poder em Roma: um mundo em transformação, Annablume. São Paulo

Fleming, M. I. D’A. 2001. Poder Político e cultura material: as vasilhas de metal romanas no contexto imperial e nas áreas periféricas da Europa central e do norte. In: Benoit, H.; Funari, P. P. A. (Orgs.) Ética e Política no Mundo Antigo. UNICAMP, Revista FAPESP, Campinas: 101-116.

Fleming, M. I. D'A. 2014. Apresentação. R. Museu Arq. Etn. Supl, n. 18, Anais do I Simpósio do Laboratório de Arqueologia Romana Provincial "Representações da romanização no mundo provincial romano": 11. 
Estruturas de poder - patronato, honra e prestígio nas representações discursivas das moedas de Aelia Capitolina e Cesareia no século III EC

R. Museu Arq. Etn., 32: 179-190, 2019.

Funari, P. P. A. 1988. Arqueologia: por quê, para quê, em benefício de quem? III Reunião Anual da Sociedade Brasileira de Estudos Clássicos, Rio de Janeiro. Caderno de Resumos: 2.

Funari, P. P. A. 1993. Roma Vida Pública e Vida Privada. $4^{\circ}$ ed. Atual, São Paulo.

Funari, P. P. A. 1997. European archaeology and two Brazilian offspring: classical archaeology and art history. Journal of European Archaeology, v. 5, n. 2: 137-148.

Funari, P. P. A. 2003a. Arqueologia. Contexto, São Paulo.

Funari, P. P. A. 2003b. Cultura material Histórica e Patrimônio. IFCH/Unicamp, Campinas.

Funari, P. P. A. 2005. The Economic history of Roman Britain: olive oil contribution to the debate. História e economia, v. 1: 29-46.

Funari, P. P. A. 2006. Latin epigraphy, an interdisciplinary approach to the ancient world. Revista Clássica, São Paulo, v. 17/18: 311-322.

Funari, P. P. A. 2008a. Brasilenos y romanos: colonialismo, identidades y el rol de la cultura material. In: Funari, P. P. A.; Pérez-Sanches, D.; Silva, G. J. (Eds.) Arqueologia e História del mundo antiguo: contribuciones brasilenas y espanolas. Oxford: BAR Internations Series 1791: 41-45.

Funari, P. P. A. 2008b. La contribution d'une approche postprocessual pour la compréhension de la consommation d'huile d'olive en Bretagne romaine. Studio Historica. Historia Antigua, v. 26: 271-302.

Garrafoni, R. S.; Cavicchioli, M.; Silva, G. J. 2001. Escavação arqueológica em uma cidade romana: a experiência de três brasileiros. Boletim do CPA, ano VI, n. 11: 149-153.

Guarinello, N. L. 1994. Memoria coletiva e historia cientifica. Revista Brasileira de Historia, São Paulo, v. 14 , n. $28: 180-93$.

Guarinello, N. L. 1995. A Economia Antiga e a Arqueologia Rural. CLASSICA, São Paulo, v. 7/8: 271-283.

Guarinello, N. L. 2005. Archaeology and the Meanings of Material Culture. In: Funari, P. P. A.; Zarankin, A; StoveL, E. (Org.) Global Archaeological theory, contextual voices and contemporary thoughts. Nova Iorque: Kluwer/Plenum, v. 1: 19-28.

Guarinello, N. L. 2006. O Império Romano e Nós (Introdução) In: Mendes, N. M.; Silva, G. V. (Orgs.) Repensando o Império Romano: perspectiva socioeconômica, politica e cultural. Mauad, Rio de Janeiro; Edufes, Vitória, ES: 13-19.
Guarinello, N. L. 2008. Império e Imperialismo, realidades antigas e conceitos contemporâneos. In: Feldman, S.A.; Campos, A.P.; Silva, G.V.; Nader, M. B.; Franco, S. P. (Orgs.) Os impérios e suas matrizes politicas e culturais. Flor \& Cultura, Vitória; Université de Paris-Est, Paris: 47-76.

Halliday, M. A. K.; Matthiessen, C. M. I. M. 2004. An Introduction to Functional Grammar. 3. ed. Edward Arnold, London.

Hingley, R. 2000. Roman officers and English gentlemen: the imperial origins of Roman Archaeology. Routledge, London.

Kress, G.; van Leeuwen, T. 2006 [1996]. Reading images: the grammar of visual design. Routledge, London.

Lacroix, L. 1974. Études d'archéologie numismatique. Universidade de Lion. Publicações da Biblioteca Salomon Reinach, Diffusion de Boccard, Paris.

Marshall, F. (Ed.) 2003. História Antiga e Arqueologia. Dossiê Projeto Apollonia. Revista Anos 90, Porto Alegre, v. 10, n. 17.

Mattingly, D.J. 1996. From one Colonialism to another: Imperialism and the Maghreb. In: Webster, J.; Cooper, N. (Orgs.) Roman Imperialism: Post-Colonial Perspectives (Leicester Archaeology Monographs, 3). Leicester: 49-69.

Munzi, M. 2001. L'epica del ritorno: archeologia e politica nella Tripolitania italiana. "L'Erma" di Bretschneider, Roma.

Pérez, C. 1986. Monnaie du pouvoir. Pouvoir de la monnaie. Une pratique discursive originale: le discours figuratif monétaire. Annales Littéraires de l'Université de Besançon, Paris.

Polanyi, K. 1944. A grande transformação - As origens de nossa época. Campus, Rio de Janeiro.

Porto, V. C. 2013. A iconografia judaica e as moedas da Judeia. Lumen et Virtus: revista de cultura e imagem, v. IV: 22-48.

Porto, V. C. 2012. As moedas romanas da Península Ibérica e da Síria-Palestina: uma tentativa de diálogo. Revista Mare Nostrum, n. 3: 13-32.

Porto, V. C. 2007. Imagens monetárias na Judéia/Palestina sob dominação romana. Tese de Doutorado. Universidade de São Paulo - MAE/USP. São Paulo.

Rech, R. M. 2003. Apollonia Romana e sua Villa Maritima. Revista Anos 90, Porto Alegre, v. 10, n. 17: 229-250.

Roll, I.; Tall, O. 1999. Apollonia-Arsuf. Final Report of Excavations I. Tel Aviv. 